\title{
INTEGRASI PASAR KOMODITAS KELAPA DAN PRODUK TURUNAN INDONESIA DENGAN PASAR DUNIA
}

\section{MARKET INTEGRATION OF INDONESIAN COCONUTS AND ITS DERIVATIVE PRODUCTS IN INTERNATIONAL MARKET}

\author{
Syahrul Ganda Sukmaya*1, Reny Hidayati ${ }^{2}$ \\ ${ }^{1,2}$ Universitas Perjuangan Tasikmalaya, Jl. Peta No. 177 Kota Tasikmalaya \\ *E-mail:syahrulganda@unper.ac.id
}

(Diterima 07-01-2020; Disetujui 16-01-2020)

\begin{abstract}
ABSTRAK
Produk kelapa merupakan komoditas ekspor tradisional Indonesia. Produk kelapa yang menjadi unggulan ekspor adalah kopra dan minyak kelapa. Penentuan harga produk ekspor kelapa yang ditentukan oleh pasar acuan dunia seringkali hanya diketahui oleh beberapa pihak saja. Asimetris informasi pasar yang diterima produsen dapat merugikan para produsen. Informasi pasar yang lancar dapat membantu meningkatkan kesejahteraan produsen dan meningkatkan kecepatan reaksi produsen terhadap perubahan kondisi pasar. Melalui penelitian Integrasi pasar ini diharapkan dapat mengetahui tingkat Integrasi pasar Indonesia dengan pasar acuan dunia. Manfaat dari penelitian ini yaitu dapat dilakukan langkah perbaikan dan antisipasi dalam meningkatkan kelancaran informasi pasar bagi produsen. Pada akhirnya dengan kelancaran informasi pasar yang diperoleh dapat meningkatkan reaksi produsen apabila terjadi perubahan pasar, serta meningkatkan kesejahteraan produsen kelapa. Untuk mengkaji integrasi pasar ini digunakan metode VAR/VECM. Hasil penelitian menunjukkan bahwa produk turunan kelapa Indonesia terintegrasi dengan pasar kelapa dunia. Pada pasar Indonesia, integrasi pasar yang terjadi antara pasar kopra Indonesia dan pasar minyak kelapa Indonesia merupakan integrasi pasar yang searah karena hanya harga minyak kelapa yang berpengaruh signifikan terhadap harga kopra Indonesia, dan tidak sebaliknya.
\end{abstract}

Kata kunci: produk kelapa, informasi pasar, VAR/VECM

\section{ABSTRACT}

Coconut products are mostly traditional export Indonesia. Coconut products seed is copra exports and coconut oil. The determination of product price coconut export determined by reference the world market often known only by some side. Asymmetrical market information received by producers can harm producers. Fluent market information can help improve the welfare of producers and increase the speed reaction producers on changes in the market. Through research, market integration is expected to determine the level of integration of Indonesian market reference world markets. Benefit from the study that can be done the next step and anticipation of to increase the market information for producers. Eventually with the market information obtained can improve producers when reaction that is a massive market, and the welfare of oil producer. To assess integration this market used method of var/vecm. The result showed that the Indonesian coconut by integrated with coconut the world market. On the Indonesian market, market integration that happened between copra market indonesia and palm oil market indonesia is market integration in line because of only coconut oil prices significant on the amount of copra Indonesia, and vice versa.

Keywords: coconut products, market information, var/vecm

\section{PENDAHULUAN}

Potensi komoditas pertanian

Indonesia sangat besar dan beragam macamnya. Ketersediaan cahaya matahari yang sepanjang tahun tersedia serta kondisi wilayah yang berbeda tiap 
daerah menyebabkan berkembangnya keanekaragaman hayati. Jika kita melihat potensi setiap wilayah dari Sabang sampai Merauke, maka akan muncul potensi pertanian yang berbeda-beda setiap wilayah. Sumatera dan Kalimantan dengan potensi perkebunan sawit dan karet, Pulau Jawa dengan komoditas pangan dan hortikulturanya, Sulawesi dengan kakao dan kelapa, serta Maluku dan Papua dengan rempah-rempah, kelapa, dan komoditas perkebunan lainnya. Oleh karena itu, dengan besarnya potensi pertanian yang dimiliki, maka Indonesia dapat menjadi pemain utama komoditas pertanian di pasar global.

Kelapa merupakan komoditas perkebunan yang dimiliki oleh Indonesia yang dapat tumbuh subur di seluruh wilayahnya. Sebelum komoditas kelapa sawit menjadi primadona seperti saat ini, kelapa adalah komoditas unggulan yang dimiliki Indonesia. Produk perdagangan yang dihasilkan oleh komoditas kelapa sangat beragam, dimana terdapat dua komoditas unggulan Indonesia berbahan baku kelapa yaitu kopra dan minyak kelapa. Kopra merupakan produk turunan berbahan baku kelapa yang telah dijemur dan dikeringkan untuk dibuat minyak, produk ini paling besar diekspor karena dijadikan bahan baku untuk industri pengolahan minyak kelapa. Sedangkan minyak kelapa merupakan minyak atsiri yang diperas dari buah kelapa, digunakan sebagai minyak makan, dalam pembuatan margarin dan sabun.

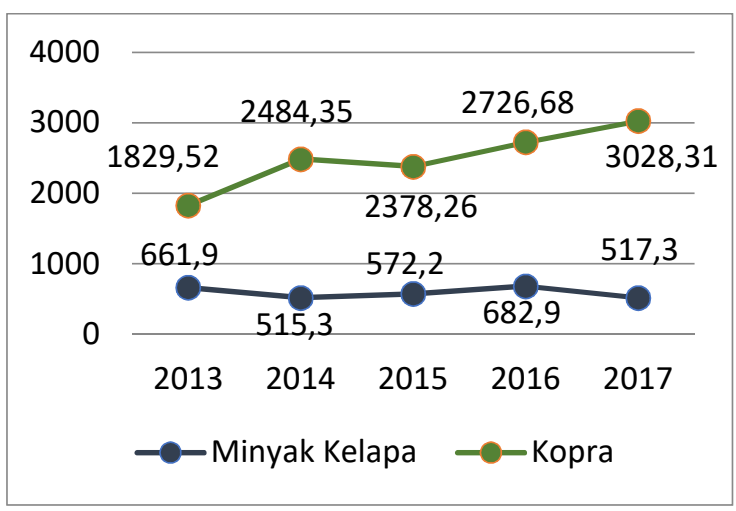

Gambar 1. Tren Nilai Ekspor Kopra dan Minyak Kelapa Tahun 2013-2017

Nilai ekspor kopra dalam rentang waktu 2013-2017 menunjukan tren yang terus meningkat. Peningkatan nilai ekspor ini menunjukkan bahwa permintaan pasar global terus berkembang. Akan tetapi berbeda halnya dengan komoditas minyak kelapa, perkembangan nilai ekspor produk ini cenderung stagnan dan menurun. Hal ini mungkin disebabkan oleh produk substitusinya yaitu minyak nabati lain seperti minyak kanola, minyak kedelai, minyak sawit, dan lain-lain. Persaingan dengan minyak nabati lainnya membuat pasar minyak kelapa menjadi komoditas alternatif karena harganya yang kurang kompetitif dengan minyak nabati lainnya. 
Harga merupakan komponen yang sangat penting dalam pemasaran produk pertanian. Komponen ini mencerminkan biaya produksi dan daya beli konsumen. Bagi produsen komponen harga merupakan daya tarik untuk memproduksi suatu barang atau jasa. Harga yang tinggi akan menarik produsen untuk memproduksi komoditas lebih banyak, begitupun sebaliknya. Tinggi dan rendahnya suatu harga komoditas juga dapat menunjukkan tingkat kesejahteraan produsen. Apabila harga yang diterima oleh produsen terlalu rendah, secara tidak langsung keuntungan yang diterimapun akan rendah dan tingkat kesejateraan produsen akan rendah.

Integrasi harga mengukur keterkaitan harga disetiap pasar yang ada. Semakin terintegrasi harga produk maka semakin baik tingkat kesejahteraan produsen. Pengukuran integrasi harga dilakukan dengan mengukur tingkat harga di wilayah sentra produksi kemudian harga ditingkat "spot market" dan dilihat juga harga di pasar dunia. Hal-hal yang dapat menjadikan harga produk tidak terintegrasi diantaranya adalah infrastruktur, saluran pemasaran yang panjang dan kebijakan pemerintah.

Harga kopra dan minyak kelapa Indonesia saat ini ditentukan oleh pasar global. Meskipun Indonesia adalah produsen besar untuk kopra dan minyak kelapa, akan tetapi tidak dapat menentukan harga komoditas ini. Ketika terjadi kenaikan harga komoditas di pasar global seringkali produsen tidak secara cepat menerima perubahan harga di tingkat global. Informasi terkait perubahan harga umumnya diterima secara cepat oleh para eksportir, akan tetapi lambat diterima oleh produsen. Hal ini sering dimanfaatkan oleh para eksportir dengan memanipulasi informasi harga ditingkat produsen, sehingga trasmisi harga dari pasar global ke produsen cenderung asimetris.

Mencegah terjadinya asimetris informasi pasar, menyediakan informasi pasar yang akurat dan berkelanjutan multak diperlukan. Jika konsumen dan produsen memiliki informasi pasar yang akurat dan berkelanjutan, maka perubahan harga dapat dengan cepat direspon oleh para pelaku pasar sehingga pengambilan keputusan dapat dilakukan secara cepat dan tepat (FAO, et al, 2011). Hal tersebut menunjukkan bahwa antara pasar yang satu dengan pasar yang lainnya telah terintegrasi dengan baik. Kondisi ini sesuai dengan Ravalion (1986) yang menyatakan bahwa dalam suatu pasar yang terintegrasi maka harga 
dari pasar yang berbeda mempunyai hubungan yang positif sebagai cerminan lancarnya arus informasi pasar.

Integrasi pasar akan tercapai jika terdapat informasi pasar yang sama, memadai, disalurkan dengan cepat ke pasar lain dan memiliki hubungan yang positif antar harga di pasar yang berbeda (Baffes and Bruce, 2003). Adanya pasar yang terintegrasi diharapkan informasi mengenai setiap perubahan harga kopra dan minyak kelapa di pasar global dapat diikuti oleh perubahan harga di tingkat produsen sehingga tidak merugikan para pelaku pemasaran yang terlibat. Pada kondisi dilapang menunjukkan bahwa besarnya perubahan harga kopra dan minyak kelapa di pasar global tidak diikuti oleh perubahan harga di tingkat produsen dengan besaran yang sama. Hal tersebut mengindikasikan bahwa informasi harga belum tersalurkan dengan baik yang berarti tingkat transmisi harga kopra dan minyak kelapa di Indonesia masih rendah. Berdasarkan hal tersebut, maka tujuan pada penelitian ini ingin mengkaji (1) Variasi harga kopra dan minyak kelapa di Indonesia, dan (2) Menganalisis tingkat integrasi pasar kopra dan minyak kelapa antara pasar spot dan pasar dunia.

\section{METODE PENELITIAN}

Penelitian ini dilakukan dengan menggunakan data sekunder. Data sekunder yang digunakan merupakan data runtun waktu (time series) bulanan dengan periode tahun 2013 - 2017. Data yang dianalisis dalam penelitian ini adalah harga kopra dan minyak kelapa dipasar spot dan pasar acuan dunia.

Untuk analisis integrasi pasar dapat diukur melalui empat pendekatan yaitu pendekatan korelasi harga, regresi sederhana, kointegrasi, dan metode VAR/VECM. Keempat metode menggunakan harga komoditi dalam bentuk time series sebagai input yang dianalisis. Pendekatan metode korelasi digunakan hanya untuk menganalisis keterkaitan harga pada dua pasar yang berbeda. Metode ini tidak memperhitungkan adanya faktor-faktor lain seperti inflasi harga secara umum, musim, pertumbuhan populasi, kebijakan perdagangan, dsb. Kelemahan dari metode ini selain karena masalah pada spurious correlation yang dapat menimbulkan kekeliruan dalam penarikan kesimpulan juga karena adanya ketidakstasioneran data yang sering terjadi. Asmarantaka (2012) menyatakan umumnya sistem pasar yang efisien memiliki derajat korelasi positif yang 
tinggi namun korelasi yang rendah tidak selalu menunjukkan pasar tidak efisien.

Pendekatan lainnya yang sering digunakan dalam menganalisis integrasi pasar adalah metode regresi sederhana. Metode ini menjelaskan bahwa harga di suatu pasar merupakan fungsi dari harga pada pasar lainnya. Keunggulan yang terdapat pada metode ini yaitu dapat menunjukkan nilai keeratan hubungan antara pasar yang terintegrasi. Namun, metode ini juga memiliki kelemahan berupa tidak dapat memisahkan harga sebagai variabel dependen maupun variabel independen karena model dalam metode ini mempunyai sifat inverse. Pada analisis ini harga-harga pasar bergerak pada waktu yang bersamaan.

Pendekatan metode kointegrasi yang dikembangkan oleh Engle dan Granger (1987) bertujuan untuk menentukan apakah variabel-variabel yang tidak stasioner terkointegrasi atau tidak. Konsep kointegrasi didefinisikan sebagai kombinasi linear antara dua atau lebih variabel yang tidak stasioner akan menghasilkan variabel yang stasioner. Persamaan kointegrasi dapat diinterpretasikan sebagai hubungan keseimbangan jangka panjang diantara variabel (Firdaus 2011). Uji kointegrasi dapat membuktikan adanya keterkaitan harga pada jangka pendek dan jangka panjang diantara pasar dalam suatu kawasan. Kelemahan yang terdapat dalam metode kointegrasi yaitu metode ini tidak memiliki prosedur sistematis untuk mengestimasi vektor kointegrasi berganda secara terpisah, selain itu tahapan estimasi dalam metode ini melalui dua tahap dimana apabila terjadi pendugaan yang error pada tahap pertama akan berlanjut ke tahap kedua.

Pendekatan Vector Autoregression Method (VAR) yang diciptakan oleh Sims (1980) merupakan salah satu pemecahan atas permasalahanpermasalahan ekonomi melalui pendekatan non-struktural. Model VAR merupakan suatu sistem persamaan dimana setiap peubah sebagai fungsi linier dari konstanta dan nilai lag (lampau) dari peubah itu sendiri serta nilai lag dari peubah lain dalam sistem. Peubah penjelas dalam VAR meliputi nilai lag dari peubah tak bebas (dependen) yang ada dalam sistem persamaan. Persamaan umum VAR adalah sebagai berikut:

$y_{t}=A_{0}+A_{1} y_{t-1}+A_{2} y_{t-2}+\ldots+A_{p} y_{t-p}+e_{t}$

Dimana:

$$
\begin{array}{r}
y_{t}=\text { vektor berukuran (n-1) yang } \\
\text { berisikan } n \text { variabel yang }
\end{array}
$$


terdapat dalam sebuah model VAR

$A_{0}=$ vektor intersep berukuran (n-1)

$A_{i}=$ matriks koefisien/parameter berukura (n.n) untuk setiap $\mathrm{i}=$ $1,2, \ldots, \mathrm{p} e_{t}=$ verktor error berukuran (n-1)

Salah satu kelemahan model VAR yaitu semua variabel yang digunakan dalam model harus stasioner. Oleh karena itu, untuk variabel nonstasioner tetapi memiliki potensi untuk terkointegrasi dianalisis menggunakan Vector Error Correction Model (VECM).

\section{HASIL DAN PEMBAHASAN}

\section{Uji Stasioneritas Data}

Data deret waktu biasanya memiliki permasalahan terhadap stasioneritas. Permasalahan stasioneritas dapat diuji dengan menggunakan uji unit root. Uji unit root dilakukan dengan menggunakan uji Augmented Dickey Fuller (ADF). Uji ini diterapkan pada masing-masing variabel yang diteliti. Variabel akan dikategorikan tidak memiliki unit root atau sudah stasioner apabila nilai mutlak t-statistik uji ADF lebih besar dibandingkan nilai mutlak critical value. Nilai t-statistik uji ADF diperoleh dari nilai Schwarz Bayesian Criterion (SBC) terkecil dari setiap variabel yang diuji atau nilai SBC mutlak terbesar dari setiap variabel yang diuji.

Tabel 1. Uji Unit Root (level)

\begin{tabular}{lllc}
\hline Variabel & \multicolumn{1}{c}{ Nilai SBC } & \multicolumn{1}{c}{$\begin{array}{l}\text { Nilai } \\
\text { ADF }\end{array}$} & $\begin{array}{c}\text { Critical } \\
\text { Value }\end{array}$ \\
\hline COPInd & -810.6752 & -1.5676 & \\
& $(-813.2341)$ & $(-1.7853)$ & -2.3567 \\
COPWrl & -689.3353 & -1.7684 & $(-$ \\
& $(-693.2653)$ & $(-1.7468)$ & $3.1254)$ \\
CCOInd & -805.8961 & -1.6679 & \\
& $(-807.4456)$ & $(-1.6587)$ & \\
\hline
\end{tabular}

Sumber: Analisis Data Primer (2019)

Keterangan:

- Nilai yang tidak dikurung adalah nilai dengan intercept tanpa linier trend

- Nilai yang dikurung adalah nilai dengan intercept dan linier trend

Data penelitian ini menunjukkan tidak stasioner pada tingkat level seperti yang ditunjukkan pada Tabel 1. Ketidakstasioneran data dikarenakan nilai mutlak ADF seluruh variabel lebih kecil dari nilai mutlak critical value. Berdasarkan hal tersebut, dapat disimpulkan bahwa data belum stasioner. Untuk mengatasi permasalahan stasioneritas ini maka uji derajat integrasi satu (first difference) harus dilakukan. Hasil dari uji derajat integrasi satu dapat dilihat pada Tabel 2.

Setelah dilakukan uji derajat integrasi satu, semua variabel stasioner, karena nilai mutlak ADF pada masingmasing variabel lebih besar dibandingkan nilai mutlak critical value. Artinya semua 
variabel stasioner pada derajat integrasi satu.

Tabel 2. Uji Unit Root (first difference)

\begin{tabular}{|c|c|c|c|}
\hline Variabel & Nilai SBC & $\begin{array}{l}\text { Nilai } \\
\text { ADF }\end{array}$ & $\begin{array}{c}\text { Critical } \\
\text { Value }\end{array}$ \\
\hline COPInd & $\begin{array}{l}-811.7843 \\
(-813.0714)\end{array}$ & $\begin{array}{l}-4.1387 \\
(-4.0264)\end{array}$ & \\
\hline COPWrl & $\begin{array}{l}-713.4285 \\
(-715.2653)\end{array}$ & $\begin{array}{l}-4.3287 \\
(-4.2367)\end{array}$ & $\begin{array}{c}-2.2486 \\
(-3.0487)\end{array}$ \\
\hline CCOInd & $\begin{array}{l}-810.7843 \\
(-811.2561)\end{array}$ & $\begin{array}{l}-4.5871 \\
(-4.5619)\end{array}$ & \\
\hline
\end{tabular}

Sumber: Analisis Data Primer (2019)

Keterangan:

- Nilai yang tidak dikurung adalah nilai dengan intercept tanpa linier trend

- Nilai yang dikurung adalah nilai dengan intercept dan linier trend

\section{Penentuan Ordo VAR}

Tahapan pendugaan model VAR dalam integrasi pasar diawali dengan menemukan lag optimal yang akan digunakan. Penentuan lag optimal atau ordo VAR didasarkan pada uji Adjusted Likelihood Ratio Test (LR Test). Hasil uji Adjusted LR Test menunjukkan model VAR yang akan digunakan adalah model VAR berordo tiga atau VAR (3).

\section{Kointegrasi}

Kointegrasi adalah suatu hubungan jangka panjang antara variabel-variabel yang meskipun secara individual tidak stasioner tetapi kombinasi linier antara variabel tersebut dapat menjadi stasioner.

Oleh karena itu, kointegrasi dapat digunakan sebagai salah satu cara untuk menghindari masalah spurious regression (regresi palsu). Salah satu cara untuk menguji kointegrasi antar variabel yaitu dengan menggunakan tes kointegrasi Johansen.

Tabel 3. Johansen Cointegration Test

\begin{tabular}{ccccc}
\hline Null & Alt. & $\begin{array}{c}\text { Trace } \\
\text { Statistic }\end{array}$ & $\begin{array}{c}\mathbf{9 5 \%} \\
\text { Critical } \\
\text { Value }\end{array}$ & $\begin{array}{c}\text { 90\% } \\
\text { Critical } \\
\text { Value }\end{array}$ \\
\hline $\mathrm{r}=0$ & $\mathrm{r} \geq 1$ & 19.8501 & 24.05 & 21.46 \\
$\mathrm{r} \leq 1$ & $\mathrm{r} \geq 2$ & 6.3152 & 12.36 & 10.25 \\
$\mathrm{r} \leq 2$ & $\mathrm{r}=3$ & 0.1367 & 4.16 & 3.04 \\
\hline Sumber:
\end{tabular}

Sumber: Analisis Data Primer

Pada Tabel 3 menunjukkan hasil Johansen Cointegration Test yang digunakan untuk mengetahui jumlah persamaan kointegrasi yang terdapat di dalam sistem. Jika Trace Statistic > Critical Value maka persamaan tersebut terkointegrasi, sedangkan jika Trace Statistic < Critical Value maka tidak terjadi kointegrasi. Jika terjadi kointegrasi, maka model yang digunakan adalah Vector Error Correction Model (VECM), sedangkan jika tidak terjadi kointegrasi maka model yang digunakan adalah VAR dengan pendifferensian.

Hasil uji Johansen pada Tabel 3, menunjukkan tidak terjadi kointegrasi karena nilai Trace Statistic lebih kecil dari pada nilai kritis 5 persen, maka model yang digunakan adalah VAR.

\section{Pendugaan Koefisien}

Setelah mendapatkan model integrasi pasar, maka selanjutnya koefisiennya dapat diestimasi dengan 
menggunakan lag optimal yang diperoleh pada tahap ordo VAR. Pengestimasian koefisien dalam model VAR dilakukan untuk melihat pengaruh dari satu variabel dengan variabel lainnya.

Tabel 4. Koefisien Model VAR Integrasi Pasar Kopra Dunia, Kopra Indonesia, dan Minyak Kelapa Indonesia

\begin{tabular}{lccc}
\hline Lag & \multicolumn{3}{c}{ Variabel Endogen } \\
& $\begin{array}{l}\text { DCOPIn } \\
\text { d }\end{array}$ & DCOPWrl & DCCOIn \\
& & & d \\
\hline $\begin{array}{l}\text { DCOPIn } \\
\text { d (-1) }\end{array}$ & 0.093 & $\mathbf{0 . 2 3 9}$ & $\mathbf{0 . 2 6 4}$ \\
$\begin{array}{l}\text { DCOPIn } \\
\text { d (-2) }\end{array}$ & $\mathbf{- 0 . 2 0 1}$ & $\mathbf{0 . 1 7 6}$ & 0.039 \\
$\begin{array}{l}\text { DCOPIn } \\
\text { d (-3) }\end{array}$ & -0.059 & $\mathbf{0 . 1 1 9}$ & 0.216 \\
$\begin{array}{l}\text { DCOPW } \\
\text { l (-1) }\end{array}$ & -0.065 & $\mathbf{- 0 . 4 4 3}$ & 0.292 \\
$\begin{array}{l}\text { DCOPW } \\
\text { rl (-2) }\end{array}$ & 0.137 & -0.145 & 0.688 \\
$\begin{array}{l}\text { DCOPW } \\
\text { rl (-3) }\end{array}$ & 0.193 & -0.077 & 0.147 \\
$\begin{array}{l}\text { DCCOIn } \\
\text { d (-1) }\end{array}$ & -0.048 & -0.050 & -0.049 \\
$\begin{array}{l}\text { DCCOIn } \\
\text { d (-2) }\end{array}$ & -0.024 & $\mathbf{0 . 1 3 5}$ & $\mathbf{- 0 . 2 7 6}$ \\
$\begin{array}{l}\text { DCCOIn } \\
\text { d (-3) }\end{array}$ & -0.131 & 0.023 & $\mathbf{- 0 . 2 9 0}$ \\
\hline
\end{tabular}

Sumber: Analisis Data Primer

Keterangan:

angka dicetak tebal nyata pada $\alpha=5 \%$

Harga kopra dunia, kopra Indonesia, dan minyak kelapa Indonesia secara nyata dipengaruhi oleh lag variabelnya masing-masing seperti terlihat pada Tabel 4. Variabel harga kopra dunia dipengaruhi oleh lag dari variabel itu sendiri. Untuk harga kopra Indonesia dan minyak kelapa, selain dipengaruhi oleh lag dari variabel itu sendiri, variabel tersebut juga dipengaruhi oleh lag dari variabel lainnya.

Harga kopra dunia dipengaruhi oleh harga kopra dunia itu sendiri pada lag kedua dengan nilai koefisien sebesar 0.201 . Nilai tersebut memiliki pengertian bahwa setiap terjadi peningkatan harga kopra dunia sebesar satu rupiah per kilogram pada dua bulan yang lalu akan mengakibatkan penurunan harga kopra dunia sebesar Rp $0.201 / \mathrm{kg}$ atau sebaliknya.

Harga kopra domestik dipengaruhi oleh harga kopra domestik itu sendiri pada lag pertama dengan nilai koefisien sebesar -0.443. Artinya, setiap terjadi peningkatan harga kopra domestik sebesar satu rupiah per kilogram pada satu bulan lalu akan mengakibatkan penurunan harga kopra domestik sebesar $\mathrm{Rp} 0.443 / \mathrm{kg}$ atau sebaliknya. Variabel lain yang mempengaruhi harga kopra Indonesia adalah harga kopra dunia pada lag pertama, kedua, dan ketiga dengan nilai koefisien sebesar $0.239,0.176$, dan 0.119 . Artinya, setiap terjadi peningkatan harga kopra dunia sebesar satu rupiah per kilogram pada satu, dua, dan tiga bulan yang lalu akan mengakibatkan kenaikan harga kopra Indonesia sebesar Rp 0.239/kg, Rp 0.176/kg, dan Rp 0.119/kg atau sebaliknya. Selain itu, harga minyak 
kelapa Indonesia pada lag kedua dengan nilai koefisien 0.135 juga mempengaruhi harga kopra Indonesia. Artinya, setiap terjadi peningkatan harga minyak kelapa Indonesia sebesar satu rupiah per kilogram pada dua bulan yang lalu akan mengakibatkan kenaikan harga kopra Indonesia sebesar Rp 0.135/kg.

Harga minyak kelapa Indonesia dipengaruhi oleh variabel harga itu sendiri pada lag kedua dan ketiga. Nilai koefisiennya masing-masing sebesar 0.276 dan -0.290 artinya, setiap terjadi peningkatan harga minyak kelapa Indonesia sebesar satu rupiah per kilogram pada dua dan tiga bulan yang lalu akan mengakibatkan penurunan harga minyak kelapa Indonesia sebesar Rp 0.276/kg dan Rp 0.290/kg. Harga kopra dunia juga mempengaruhi harga minyak kelapa Indonesia pada lag pertama dengan nilai koefisien 0.264 yang artinya, jika harga kopra dunia mengalami kenaikan pada satu bulan yang lalu sebesar satu rupiah per kilogram maka harga minyak kelapa Indonesia akan naik sebesar nilai koefisiennya, yaitu Rp 0.264/kg.

\section{Integrasi Pasar Kopra Dunia, Kopra Indonesia, dan Minyak Kelapa Indonesia \\ Berdasarkan hasil estimasi} koefisien VAR dapat dianalisis hal-hal mengenai integrasi pasar serta variabel yang mempengaruhinya. Harga kopra Indonesia dipengaruhi oleh tiga variabel yaitu harga kopra dunia, harga kopra Indonesia itu sendiri dan harga minyak kelapa Indonesia. Adanya perambatan harga dari lag harga kopra dunia mengindikasikan terjadinya integrasi pasar antara pasar kopra dunia dengan pasar kopra Indonesia.

Pada integrasi pasar antara pasar kopra dunia dan pasar kopra Indonesia, karena harga kopra dunia yang ikut menentukan pembentukan harga kopra di dalam negeri, sedangkan harga kopra Indonesia tidak ikut menentukan pembentukan harga kopra dunia, dengan demikian dalam integrasi pasar tersebut pasar kopra dunia berperan sebagai pemimpin harga, sedangkan pasar kopra Indonesia berperan sebagai pengikut harga. Hal ini dikarenakan, Indonesia adalah negara kecil dalam perdagangan kopra dunia.

Variabel harga kopra dunia yang mempengaruhi harga kopra Indonesia, harga minyak kelapa Indonesia juga mempengaruhi harga kopra Indonesia. 
Hal ini disebabkan adanya struktur pasar yang cenderung oligopsoni di mana pemegang hak oligopsoni adalah pabrik miyak kelapa dan pemasaran hasil kopra dikuasai oleh kerjasama antara pedagang dan industri. Selain itu, sebagian besar industri kopra juga diusahakan oleh rakyat yang mana memiliki daya tawar yang rendah terhadap industri.

Adanya integrasi pasar domestik tersebut mengindikasikan adanya informasi pasar yang baik akan menjadi sangat penting karena dapat mendatangkan keuntungan yang lebih baik bagi pelaku industri kopra. Asimetris informasi pasar tentang mutu kopra kepada produsen menyebabkan nilai tambah dari hasil pemasaran tidak dinikmati oleh produsen tetapi pedagang.

Harga minyak kelapa Indonesia dipengaruhi oleh dua variabel yaitu harga kopra dunia dan harga minyak kelapa itu sendiri. Adanya pengaruh harga dari kopra dunai mengindikasikan terjadinya integrasi pasar antara pasar minyak kelapa Indonesia dengan pasar kopra dunia, dimana hanya harga kopra dunia yang mempengaruhi harga minyak kelapa Indonesia dan tidak sebaliknya.

Harga kopra dunia dapat mempengaruhi harga minyak kelapa Indonesia dikarenakan jika terdapat peningkatan harga kopra di pasar dunia, maka akan mendorong produsen bahan baku industri minyak kelapa Indonesia yaitu kopra ke pasar dunia dalam jumlah yang sangat besar yang pada akhirnya akan menyebabkan ketidakstabilan pasokan di dalam negeri untuk industri minyak kelapa tersebut sehingga akan menyebabkan naiknya harga minyak kelapa Indonesia.

\section{KESIMPULAN DAN SARAN}

Berdasarkan

uraian dalam pembahasan, maka didapatkan kesimpulan:

1. Pasar Kopra dan pasar minyak kelapa Indonesia terintegrasi dengan pasar kopra dunia secara satu arah.

2. Pada pasar Indonesia, integrasi pasar yang terjadi antara pasar kopra Indonesia dan pasar minyak kelapa Indonesia merupakan integrasi pasar yang searah karena hanya harga minyak kelapa yang berpengaruh signifikan terhadap harga kopra Indonesia, dan tidak sebaliknya.

\section{UCAPAN TERIMA KASIH}

Peneliti dengan ini mengucapkan terima kasih kepada Universitas Perjuangan Tasikmalaya. Ucapan terima kasih disampaikan atas dukungan materil 
terhadap penelitian ini dikarenakan penelitian ini merupakan bagian dari Dana Hibah Penelitian Dosen Pemula Tahun Akademik 2018/2019.

\section{DAFTAR PUSTAKA}

Asmarantaka RW. 2012. Pemasaran Agribisnis (Agrimarketing). Bogor (ID): Departemen Agribisnis FEM IPB.

Bailey D.V, Brorsen BW. 1989. Price Asymmetry in Spatial Fed Cattle Markets. Western Journal of Agricultural Economics, 14(2): 246-252.

EngleRF, Granger CWJ. 1987. Cointegration and error correction: Representation, estimation and testing. Econometrica. 55(2): 251276.

Firdaus M. 2011. Aplikasi Ekonometrika Data Panel dan Data Time Series. Bogor (ID): IPB Press.

Hanafiah AM, Saefuddin AM. 2010. Tataniaga Hasil Perikanan. Jakarta (ID): Universitas Indonesia.

Hudson D. 2007. Agricultural Markets and Prices. United Kingdom (UK): Blackwell Publishing.

Irawan B. 2007. Fluktuasi Harga, Transmisi Harga dan Margin Pemasaran Sayuran dan Buah. Analisis Kebijakan Pertanian, 5(4): 358-373.

Karantininis K, Katrakilidis, Persson. 2011. Price Transmission in the Swedish Pork Chain: Asymmetric non linear ARDL. Paper presented at the EAAE 2011 Congress, Zurich, Switzerland.

Krugman PR, Obstfeld M. 2003. International Economic Theory and
Policy. United States of America (US): Addison Wesley.

Meyer J, von Cramon-Taubadel S. 2004. Asymmetric Price Transmission: A Survey. Journal of Agricultural Economics, 55(3): 581-611.

Miller DJ, Hayenga ML 2001. Price Cycles and Asymetric Price Tansmission in the US Pork Market. American Journal of Agricultural Economics, 83(3): 551-562.

Peltzman, S. 2000. Prices Rise Faster than they fall. Journal of Political Economy, 108(3):466-502.

Ravallion M. 1986. Testing market integration. American Journal of Agricultural Economics. 68(1): 102-109.

Sahara, Wicaksena B. 2013. Asymetry in Farm-Retail Price Transmission: The Case of Chili Industry in Indonesia. Jurnal Ekonomi dan Kebijakan Pembangunan, 2(1): 113.

Serra T, Goodwin BK. 2002. Price Transmission and Asymetric Adjustment in the Spanish Dairy Sector. Paper presented at 2002 AAEA-WAEA Annual Meeting.

Tomek GW, Robinson KL. 1990. Agricultural Product Prices. London (GB): Cornell University Press.

Vavra P, Goodwin BK. 2005. Analysis of Price Transmission Along Food Chain. Working Papers OECD Food, Agriculture and Fisheries, No 3, OECD Publishing.

Vinuya FD. 2007. Testing for Market Integration and The Law Of One Price in World Shrimp Markets. Aquaculture Economics and Management, 11(3):243-65. 